\title{
ANALISIS KOMPARATIF ABNORMAL RETURN DAN TRADING VOLUME ACTIVITY BERDASARKAN POLITICAL EVENT (EVENT STUDY PADA PENGESAHAN RUU KPK 2019)
}

\author{
Maulana Faizal Hafidz \\ Universitas Negeri Surabaya \\ maulanahafidz16080574008@mhs.unesa.ac.id \\ Yuyun Isbanah \\ Universitas Negeri Surabaya \\ yuyunisbanah@unesa.ac.id
}

Abstract

This research aims to analyze the reaction of the Indonesia capital market with average abnormal return (AAR) and cumulative abnormal return (CAR) before-after the legality of KPK law revision in 2019. This research also using trading volume activity to describe the react of capital market before-after the legality of KPK law revision in 2019. This research use event study for analysis method with 5 days before and 5 days after the event with secondary data from the Indonesia capital market. The research testing by Paired Sample T-Test and Kolmogorov-Smirnov. The result of Kolmogorov-Smirnov shows that AAR, CAR, and TVA are normal distribution. The result of the paired sample t-test shows that no difference between average abnormal return and trading volume activity before-after the political event because investors already get bad news on before and after the legality of KPK law revision in 2019 which make investor wait and see. But, the paired sample t-test shows the difference between CAR before-after the legality of KPK law revision in 2019, because the investor gets a positive abnormal return on $t-3$ and $t-4$ which make a different cumulative abnormal return.

Keywords: average abnormal return; cumulative abnormal return; event study; trading volume.

\section{PENDAHULUAN}

Pasar modal dapat dijadikan sebagai pilihan alternatif perusahaan untuk memaksimalkan kelebihan dana yang dimiliki oleh investor untuk di investasikan ke perusahaan untuk mencukupi kebutuhan dana perusahaan dan investor mendapat return yang diinginkan, Pasar modal merupakan tempat bertemunya investor selaku pemberi dana dengan pihak membutuhkan modal dengan melakukan jual beli saham atau menjadi Lembaga Perantara (Tandelilin, 2010:26).

Menurut penelitian Dewi et al., (2017), salah satu instrumen ekonomi yang tidak dapat lepas dari faktor ekonomi maupun non-ekonomi adalah pasar modal. Peristiwa politik merupakan salah satu faktor nonekonomi yang mampu memicu fluktuasi di pasar modal dan memengaruhi kestabilan perekonomian suatu negara. Bentuk Political events menurut Bouoiyour \& Selmi, (2017) salah satunya adalah perubahan pemerintahan dan perubahan kebijakan pemerintah dalam negeri ataupun luar negeri.

Menurut Nestary et al., (2017), pasar modal tidak terpengaruh politic events secara langsung, namun kandungan informasi yang diserap oleh investor untuk memperoleh keuntungan dan memengaruhi keputusan berinvestasi, sehingga pasar modal bereaksi. Abnormal return akan didapatkan oleh pasar apabila informasi terkandung dalam suatu peristiwa.

Menurut Suryawijaya et al., (2004) dalam Wardhani (2012), trading volume activity juga dapat digunakan sebagai tolok ukur reaksi pasar modal. Apabila peningkatan trading volume activity disebabkan karena permintaan yang meningkat maka dapat menjadi indikasi bahwa investor mendapat good news. Apabila peningkatan TVA disebabkan karena penjualan yang tinggi maka dapat mengindikasikan bahwa investor mendapat bad news.

Tanggal 17 September 2019, Presiden Indonesia Ir. Joko Widodo mengesahkan Revisi Undang-Undang KPK usulan DPR RI (Tempo, 2019). Beberapa pihak menganggap bahwa perubahan RUU-KPK 
terindikasi bermuatan kepentingan-kepentingan politik, hal tersebut sesuai dengan BBC (2019) bahwa pengesahan RUU KPK memiliki muatan kepentingan politik dari politisi. Kebijakan pemerintah dalam merevisi Undang-undang KPK mendapatkan aksi penolakan dari kalangan mahasiswa, dikutip dari laporan Kompas (2019) pengesahan RUU KPK ditolak dari kalangan mahasiswa karena dinilai bisa melemahkan kinerja KPK. Penolakan Revisi Undang-undang KPK juga mendapat penolakan dari kalangan akademisi, hal tersebut dimuat dalam laporan berita Tempo (2019), aksi penolakan pengesahan RUU KPK juga datang dari kalangan Akademisi. Kebijakan pemerintah dalam pengesahan revisi undang-undang KPK mendapat respon dari pasar modal, Menurut laporan Kompas (2019), dampak dari pengesahan RUU KPK adalah menurunnya kepercayaan investor yang akan masuk ke pasar modal Indonesia. Hal tersebut memperjelas bahwa pengesahan revisi undang-undang KPK (RUUKPK) pada tanggal 17 September 2019 mendapat banyak penolakan dari berbagai kalangan, termasuk pasar modal yang merespon informasi atau berita dari peristiwa tersebut, yang dapat diamati pada gambar 1.

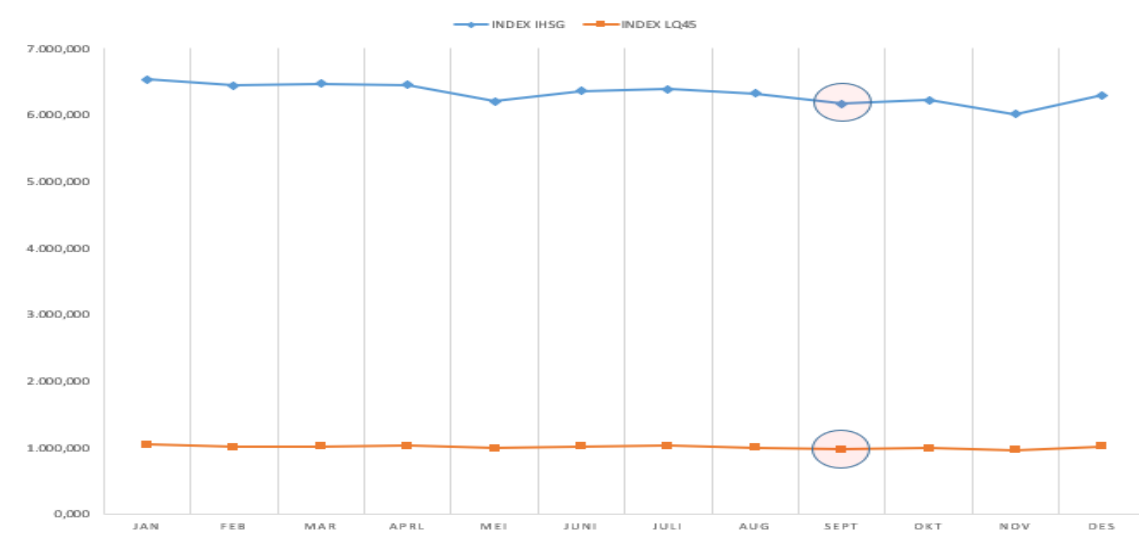

Sumber: idx.co.id (2020, data diolah)

\section{Gambar 1. GRAFIK INDEKS IHSG DAN LQ45 PADA PERIODE BULAN JANUARI 2019- DESEMBER 2019}

Gambar 1 menunjukkan bahwa bulan September menjadi salah satu bulan yang memiliki indeks paling rendah pada Indeks LQ45 setelah bulan November dalam kurun waktu Januari 2019 sampai Desember 2019 yaitu dengan nilai 968,147. Data menunjukkan bahwa terjadi net sell atau jual bersih dari pasar modal sejumlah Rp1,53 T, hal tersebut tanda investor tidak percaya kepada sistem penegakan hukum. Hal tersebut mencerminkan bahwa kandungan informasi pada pengesahan RUU KPK memiliki muatan negatif atau bad news, sehingga informasi yang didapat investor memberikan reaksi ke pasar modal. Gambar 1 juga menunjukkan Indeks Harga Saham Gabungan (IHSG) periode Januari 2019-Desember 2019 menjadikan bulan September 2019 menjadi bulan terendah kedua dengan nilai 6169,102 setelah bulan November 2019 dengan nilai 6011,830 (Detik.com, 2019).

Gambar 1 menunjukkan bahwa Indeks saham LQ45 dan IHSG cenderung memiliki tren penurunan di sekitar peristiwa penetapan Revisi Undang-Undang KPK (RUU KPK), tren penurunan pada indeks LQ45 dimulai dari tanggal 19 September 2019 sampai 30 September 2019. Sehingga, pada bulan September 2019 terdapat informasi-informasi yang diindikasikan menjadi informasi buruk (bad news) ataupun informasi baik (good news) yang memengaruhi investor dalam mengambil keputusan berinvestasi. Pasar diharapkan bereaksi terhadap informasi yang terkandung dalam pengumuman. Penjelasan tersebut dapat mengindikasikan bahwa pasar modal bereaksi terhadap kandungan informasi pada Pengesahan Revisi Undang-Undang KPK 2019, dilihat dari indeks IHSG maupun indeks LQ45 yang cenderung menurun pada sekitar tanggal peristiwa, sehingga menjadi menarik untuk meneliti abnormal return dan trading volume activity pada sebelum-sesudah Pengesahan RUU KPK 2019.

Peristiwa ini dapat diamati menggunakan Event study, yaitu kajian ilmu yang mempelajari peristiwa dan informasi yang dapat dipublikasikan menjadi pengumuman sehingga dapat memengaruhi reaksi 
pasar modal. Event study dilakukan untuk uji kandungan informasi dalam suatu kejadian (Hartono, 2017:644).

Penelitian ini bertujuan untuk mencari perbedaan abnormal return yang didapatkan investor dan trading volume activity sebelum dan sesudah terjadinya pengesahan RUU KPK 2019 sehingga dapat melihat perbedaan reaksi pasar modal sebelum dan sesudah mendapat informasi dari suatu peristiwa.

\section{KAJIAN PUSTAKA DAN PENGEMBANGAN PENELITIAN.}

\section{Signaling Theory}

Signaling theory mengasumsikan bahwa investor bertindak sesuai dengan informasi yang diterima. Peristiwa yang menimbulkan sinyal positif akan menyebabkan pasar bereaksi, sebaliknya apabila peristiwa memberikan sinyal negatif menyebabkan pasar tidak bereaksi. Investor akan meningkatkan intensitas penawaran jika memiliki sudut pandang baik terhadap informasi yang diterima. Sebaliknya, jika investor memiliki sudut pandang buruk terhadap informasi yang diterima maka intensitas penjualan akan meningkat (Gratias \& Mustanda, 2015).

\section{Event Study}

Menurut Hartono (2017:644), dalam kegunaannya, event study digunakan untuk melakukan uji informasi dalam peristiwa. Hal tersebut ditujukan untuk mengetahui reaksi yang diakibatkan peristiwa, apabila terkandung informasi diharapkan pasar modal memberikan reaksi pada saat pengumuman diterima pasar. Menurut Tandelilin (2010:565), informasi yang diterima pasar dapat berupa good news atau bad news.

\section{Efisiensi Pasar}

Efisiensi pasar adalah konsep pasar dalam menyerap informasi yang diterima sehingga memengaruhi harga saham (Tandelilin, 2010:218). Bentuk pasar efisien dibagi oleh Fama (1970) dalam Tandelilin (2010:223) menjadi 3 hipotesis, yaitu weak form, semi strong, strong form.

\section{Abnormal Return}

Abnormal return merupakan selisih actual return dan expected return (Hartono, 2017:668), yang dihitung menggunakan rumus (1).

$R T N_{i, t}=R_{i, t}-E\left[R_{i, t}\right]$

\section{Average Abnormal Return}

Average abnormal return didapat dengan menguji rata-rata abnormal return seluruh sekuritas per-hari pada event windows (Hartono, 2017:680), dihitung menggunakan rumus (2).

$A A R_{t}=\frac{\sum_{i=1}^{k} A R_{i t}}{k}$

\section{Cumulative Abnormal Return}

Cumulative abnormal return merupakan jumlah abnormal return setiap sekuritas pada event windows dengan cara menjumlahkan abnormal return sebelumnya didalam event windows (Hartono, 2017:684), yang dihitung dengan rumus (3).

$C A R_{i t}=\sum_{a=t 3}^{t} A R_{i a}$

\section{Trading Volume Activity}

Suryawijaya et al., (2004) dalam Wardhani (2012) mengatakan bahwa meningkatnya trading volume activity adalah bentuk reaksi pasar modal terhadap suatu informasi yang terkandung dalam peristiwa yang dapat dihitung dengan rumus (4). Sedangkan, rata-rata TVA dihitung dengan rumus (5). 
Maulana Faizal Hafidz \& Yuyun Isbanah. Analisis Komparatif Abnormal Return dan Trading Volume Activity berdasarkan Political Event (Event Study pada Pengesahan RUU KPK 2019)

$$
\begin{aligned}
& T V A=\frac{\sum \text { Saham perusahaan }_{-i} \text { yang ditransaksikan pada hari }}{t} . \\
& \bar{X} T V A=\frac{\sum_{i=1}^{n} T V A_{i}}{n} \ldots \ldots \ldots(5)
\end{aligned}
$$

\section{Hubungan antar Variabel}

Menurut Dewi et al., (2017) adanya perubahan average abnormal return dalam peristiwa artinya informasi didalam peristiwa cukup besar dan kuat sehingga dapat menyebabkan beda rata-rata abnormal return. Sehingga signaling theory yang mengindikasikan informasi yang diperoleh investor dalam peristiwa dapat diterima dengan baik oleh investor. Adanya perbedaan average abnormal return pada sebelum-sesudah peristiwa ditunjukkan pada penelitian Dewi et al., (2017) yang menyatakan bahwa adanya beda average abnormal return sebelum-sesudah pemilihan Gubernur Jakarta tahun 2017 disebabkan karena kandungan informasi yang kuat sehingga dapat memengaruhi reaksi pasar modal Indonesia. Namun penelitian lain yang dilakukan oleh Mahmood et al., (2014) menyatakan bahwa tidak cukup kuat informasi yang terkandung dalam politic event di Pakistan untuk mereaksi pasar modal.

H1: Sebelum dan setelah Pengesahan Revisi Undang-Undang KPK terdapat beda average abnormal return.

Menurut Pratama et al., (2015), peristiwa dalam suatu negara akan menimbulkan reaksi pasar modal. Reaksi tersebut disebabkan karena informasi di sekitar peristiwa tersebut yang diterima oleh investor. Menurut Wardhani (2012), Perbedaan signifikan pada abnormal return saham di sekitar peristiwa dapat diartikan pasar modal utamanya di Indonesia memiliki sensitifitas yang bertambah tinggi dengan informasi yang terkandung dalam non-economic events dan politic events. Penelitian yang dilakukan Nisa et al., (2019) menyatakan bahwa ada beda cumulative abnormal return pada sebelum-sesudah merger dan akuisisi perusahaan pada tahun 2016-2018 disebabkan karena investor mendapatkan informasi secara masif sesudah peristiwa. Bimantara et al., (2019) juga mengatakan bahwa ada beda cumulative abnormal return sebelum-sesudah pengumuman perhitungan baru indeks LQ45 dan IDX30 disebabkan karena informasi yang diterima oleh investor.

H2: Sebelum dan setelah Pengesahan Revisi Undang-Undang KPK terdapat beda cumulative abnormal return.

Menurut Rundengan et al., (2017) trading volume activity adalah aktivitas transaksi perdagangan di bursa saham dan merupakan cerminan dari keputusan investor dalam melakukan investasi, dimana semakin besar volume transaksi maka semakin informatif berita yang diterima oleh investor, sehingga dapat memberikan keputusan untuk membeli atau menjual saham. Hal tersebut sejalan dengan signaling theory yaitu investor memberikan kehendak atau keputusan sesuai dengan informasi yang diterima oleh investor. Dewi et al., (2017) perubahan pada volume perdagangan saham dapat memungkinkan terjadinya beda rata-rata trading volume activity sebelum-sesudah terjadinya peristiwa. Penelitian yang dilakukan oleh Oktaviani et al., (2016) menyatakan adanya beda trading volume activity sebelumsesudah pengumuman buy back saham pada perusahaan yang tergabung pada BEI, hal tersebut terjadi karena perubahan volume perdagangan sebelum-sesudah pengumuman. Hasil lain ditunjukkan pada penelitian yang dilakukan oleh Al farisi \& Nuzula (2018) yang mengatakan tidak ada beda sebelumsesudah penetapan kebijakan B20 tahun 2018 disebabkan karena tidak adanya perubahan volume perdagangan yang cukup besar sebelum-sesudah peristiwa.

H3: Sebelum dan setelah Pengesahan Revisi Undang-Undang KPK terdapat beda rata-rata trading volume activity.

\section{METODE PENELITIAN}

Jenis penelitian ini adalah penelitian komparatif, dan event study, yaitu membandingkan AAR, CAR dan TVA investor sebelum- sesudah mendapatkan informasi dari peristiwa Penetapan Revisi UndangUndang KPK tahun 2019. Menurut Hartono (2017:644) Dalam kegunaannya, event study digunakan untuk melakukan uji informasi dalam peristiwa. Hal tersebut ditujukan untuk mengetahui reaksi yang 
diakibatkan peristiwa, apabila terkandung informasi diharapkan pasar modal memberikan reaksi pada saat pengumuman diterima pasar. Menurut Tandelilin (2010:565), informasi yang diterima pasar dapat berupa good news atau bad news.

Jenis data penelitian ini adalah kuantitatif dengan data sekunder yang diambil melalui website resmi BEI, www.idx.co.id dan www.investing.com. Populasi penelitian ini adalah seluruh saham yang tergabung pada Indeks LQ45 pada periode bulan September 2019 sejumlah 45 perusahaan dengan metode pengambilan sampel dengan Teknik Sampel Jenuh, yaitu keseluruhan populasi digunakan sebagai sampel. Teknik analisis data menggunakan Paired Sample T-Test pada IBM SPSS 23.

\section{HASIL DAN PEMBAHASAN}

\section{Hasil Uji Normalitas}

Tabel 1.

UJI NORMALITAS

\begin{tabular}{ccc}
\hline Variabel & Periode & Sig. \\
\hline AAR & Sebelum & .200 \\
& Sesudah & .200 \\
CAR & Sebelum & .200 \\
& Sesudah & .200 \\
TVA & Sebelum & .200 \\
Sumber: SPSS (2020, data diolah) & .161 \\
\hline
\end{tabular}

Setelah Uji Statistik Deskriptif, selanjutnya melakukan Uji Normalitas yang bertujuan untuk melihat normalitas data yang telah diperoleh peneliti. Kolmogorov-smirnov digunakan untuk melakukan uji normalitas. Tabel 1 menunjukkan data average abnormal return, cumulative abnormal return, dan trading volume activity telah terdistribusi normal karena nilai Sig $>0,05$.

\section{Hasil Uji Hipotesis}

Tabel 2.

UJI PAIRED SAMPLE T-TEST

\begin{tabular}{cccc}
\hline Variabel & Sig. & Hasil & Keterangan \\
\hline AAR & .412 & Tidak ada beda & H0 diterima \\
CAR & .004 & Ada beda & Ha diterima \\
TVA & .385 & Tidak ada beda & H0 diterima \\
\hline
\end{tabular}

Sumber: SPSS (2020, data diolah)

Uji Hipotesis menggunakan Paired Sample T-Test karena seluruh data terdistribusi secara normal. Hasil Uji Hipotesis pada tabel 2, variabel AAR tidak ada beda sebelum-sesudah Penetapan Revisi UndangUndang KPK tahun 2019, sehingga hasil penelitian tersebut tidak dapat mendukung H1, pada Tabel 2 juga menunjukkan bahwa variabel TVA juga tidak ada beda sebelum-sesudah penetapan Revisi Undang-Undang KPK tahun 2019, sehingga hasil penelitian tersebut tidak mendukung H3. Sedangkan variabel CAR pada tabel 2 hasil uji beda menunjukkan adanya perbedaan sebelum-sesudah Penetapan Revisi Undang-Undang KPK tahun 2019, sehingga dapat mendukung H2.

\section{Perbedaan AAR sebelum-sesudah Pengesahan RUU KPK 2019.}

Hasil penelitian menunjukkan tidak ada beda AAR sebelum-sesudah Pengesahan Revisi UndangUndang KPK tahun 2019 sehingga hasil penelitian ini menolak H1 yaitu adanya beda average abnormal return sebelum-sesudah Pengesahan RUU KPK 2019. Hasil penelitian tersebut diperkuat dengan data penelitian pada tabel 3 yaitu AAR pada sekitar tanggal Pengesahan Revisi Undang-Undang KPK 2019 
yang mayoritas negatif, baik pada sebelum-sesudah tanggal Pengesahan Revisi Undang-Undang KPK 2019 yang menunjukkan bahwa investor lebih mendapatkan bad news pada sekitar tanggal peristiwa akibatnya investor cenderung mendapatkan abnormal return bernilai negatif pada sebelum dan sesudah peristiwa Pengesahan Revisi Undang-Undang KPK 2019. Menurut Hartono (2017:644) yang berkaitan dengan signaling theory bahwa, Abnormal return merupakan indikator pasar bereaksi terhadap kandungan informasi dalam pengumuman, yang dapat membuat nilai perusahaan berubah dan investor bereaksi dalam bentuk naik atau turunnya harga saham.

Tabel 3.

\section{AAR, CAR, TVA SEKITAR TANGGAL PENETAPAN RUU KPK 2019}

\begin{tabular}{cccc}
\hline Var. & AAR & CAR & TVA \\
\hline $\mathbf{t}-\mathbf{5}$ & .1461 & .0032 & .0012 \\
$\mathbf{t}-\mathbf{4}$ & .4949 & .0078 & .0014 \\
$\mathbf{t}-\mathbf{3}$ & .2635 & -.0051 & .0012 \\
$\mathbf{t}-\mathbf{2}$ & .0896 & -.0039 & .0009 \\
$\mathbf{t}-\mathbf{1}$ & -.2403 & -.0073 & .0015 \\
$\mathbf{t}+\mathbf{1}$ & -.1072 & -.0024 & .0011 \\
$\mathbf{t}+\mathbf{2}$ & -.357 & -.0056 & .0009 \\
$\mathbf{t}+\mathbf{3}$ & -.2642 & .0021 & .0015 \\
$\mathbf{t}+\mathbf{4}$ & -.6109 & -.0077 & .0009 \\
$\mathbf{t}+\mathbf{5}$ & -.9368 & -.0072 & .0011 \\
\hline
\end{tabular}

Sumber: investing.com (2020, data diolah)

Hasil penelitian ini dijelaskan dalam Nestary (2017) bahwa tidak ada beda AAR sebelum-sesudah peristiwa, artinya investor melakukan wait and see akibat ketidakpastian kondisi politik yang terjadi. Hasil penelitian ini sesuai dengan Pratama et al., (2015) yaitu tidak ada beda AAR sebelum-sesudah Peristiwa karena investor cenderung wait and see akibat informasi eksternal yang diterima. Hasil ini berbeda dengan penelitian Dewi et al., (2017) yang mengatakan ada beda AAR saham perusahaan pada Indeks LQ45 di sekitar tanggal Pilgub DKI Jakarta Tahun 2017.

Sesuai Hasil Penelitian dan Pembahasan tersebut, disimpulkan bahwa AAR sebelum-sesudah Pengesahan RUU KPK 2019 tidak terdapat beda disebabkan karena investor cenderung sudah bereaksi terhadap informasi sejak sebelum tanggal Pengesahan RUU KPK 2019 yang ditunjukkan dari nilai AAR negatif pada periode sebelum Pengesahan RUU KPK yaitu pada $t-3, t-2$, dan $t-1$ yang dapat menjadi indikasi bahwa informasi yang diterima adalah bad news kemudian melakukan wait and see akibat dari ketidakjelasan kondisi politik dan informasi eksternal yang ada.

\section{Perbedaan CAR sebelum-sesudah pengesahan RUU KPK 2019.}

Penelitian ini membuktikan ada beda CAR periode sebelum-sesudah Pengesahan Revisi UndangUndang KPK 2019. Hasil penelitian ini menerima H2 yaitu terdapat perbedaan CAR sebelum-sesudah Pengesahan Revisi Undang-Undang KPK 2019. Hasil penelitian tersebut diperkuat dengan data CAR sebelum-sesudah Pengesahan RUU KPK 2019 pada tabel 3 yaitu terdapat CAR bernilai positif yang cukup besar pada t-4 dan t-3 yang dapat memengaruhi CAR sebelum Pengesahan RUU KPK 2019. Hal tersebut sesuai dengan signaling theory dalam penelitian Susanti (2015), apabila return yan didapat investor adalah positif dan lebih besar dari yang diharapkan maka peristiwa tersebut adalah good news, begitu sebaliknya.

Hasil ini sesuai dengan Nisa et al., (2019) adanya beda CAR sebelum-sesudah peristiwa menunjukkan bahwa adanya informasi dalam peristiwa memengaruhi return meskipun tidak seluruhnya berpengaruh positif. Penelitian ini mendukung penelitian Bimantara et al., (2019) yaitu ada beda CAR sebelumsesudah Pengumuman Perhitungan Baru Indeks LQ45 dan IDX30 disebabkan informasi yang diterima oleh investor. 
Sesuai hasil penelitian dan pembahasan tersebut, disimpulkan adanya beda CAR sebelum-sesudah Pengesahan Revisi Undang-Undang KPK disebabkan karena Investor mendapat CAR bernilai positif yang cukup besar pada t-4 yang dapat memengaruhi abnormal return secara kumulatif pada sebelum peristiwa. Sesudah Pengesahan Revisi Undang-Undang KPK 2019 investor mendapatkan CAR negatif yang menjadi indikasi bahwa investor telah menyerap bad news pada peristiwa ini sehingga membuat perbedaan cumulative abnormal return.

Penelitian ini menunjukkan bahwa tidak terdapat beda AAR sebelum-sesudah peristiwa namun hasil CAR menunjukkan adanya beda sebelum-sesudah peristiwa, hal tersebut menunjukkan bahwa abnormal return yang didapat investor per-hari yang diukur menggunakan average abnormal return tidak mengalami beda karena rata-rata nilai average abnormal return bernilai negatif pada sebelumsesudah pengesahan RUU KPK sehingga tidak ada perbedaan yang cukup besar untuk membuat beda AAR sebelum-sesudah. Hasil CAR menunjukkan adanya beda sebelum-sesudah peristiwa, artinya abnormal return yang didapat investor secara kumulatif terdapat perbedaan yang cukup besar yaitu pada t-3 dan t-4 sehingga memengaruhi perbedaan CAR sebelum-sesudah pengesahan RUU-KPK 2019.

\section{Perbedaan TVA sebelum-sesudah peristiwa RUU KPK 2019.}

Hasil penelitian menunjukkan tidak ada beda TVA sebelum-sesudah Pengesahan RUU KPK 2019. Hasil penelitian ini menolak $\mathrm{H} 3$ yaitu ada beda trading volume activity sebelum-sesudah Pengesahan Revisi Undang-Undang KPK tahun 2019. Hasil penelitian ini diperkuat data trading volume activity di sekitar peristiwa pada tabel 3 yang menunjukkan bahwa data trading volume activity tidak mengalami perubahan yang cukup besar sehingga tidak membuat perbedaan TVA sebelum dan sesudah Penetapan RUU KPK 2019. Hasil ini sesuai dengan signaling theory menurut Hartono (2009:392) dalam Gratias \& Mustanda (2015) yang mengatakan bahwa peristiwa yang memuat sinyal positif membuat pasar modal bereaksi, apabila bermuatan sinyal negatif maka pasar modal tidak bereaksi sehingga akan menambah penawaran dan mengurangi pembelian akibatnya harga saham turun.

Hasil ini dijelaskan dalam penelitian Rofiki et al., (2018) yaitu apabila tidak ada perbedaan TVA sebelum-sesudah peristiwa, maka informasi yang terkandung dalam peristiwa tidak memengaruhi trading volume activity dan investor cenderung wait and see walaupun ada abnormal return bernilai negatif. Hasil penelitian ini sesuai dengan Al farisi \& Nuzula (2018) yang mengatakan tidak ada beda TVA sebelum-sesudah Pengumuman Kebijakan B20 disebabkan karena tidak adanya perubahan trading volume activity yang cukup besar untuk membuat perbedaan TVA sebelum dan sesudah peristiwa.

Sesuai dengan hasil penelitian dan pembahasan tersebut, tidak adanya beda TVA sebelum-sesudah Pengesahan Revisi Undang-Undang KPK 2019 disebabkan karena kecenderungan investor wait and see dengan kondisi politik tersebut, sehingga TVA tidak mengalami perubahan volume yang cukup besar untuk membuat perbedaan TVA sebelum-sesudah Pengesahan Revisi Undang-Undang KPK 2019.

\section{KESIMPULAN.}

Berdasarkan hasil pengujian ini, dapat disimpulkan tidak ada beda Average abnormal return dan trading volume activity sebelum-sesudah Pengesahan Revisi Undang-Undang KPK tahun 2019 disebabkan karena sikap investor yang cenderung wait and see. Hasil CAR yang menunjukkan beda sebelum dan sesudah Pengesahan RUU KPK 2019 disebabkan nilai positif CAR yang cukup besar pada t-4 yang memengaruhi CAR secara kumulatif pada periode penelitian. Implikasi teoritis penelitian ini sejalan dengan signaling theory, yaitu investor menyerap kandungan informasi. Implikasi praktis penelitian ini adalah peristiwa Pengesahan Revisi Undang-Undang KPK 2019 belum bisa sepenuhnya dijadikan acuan menilai reaksi pasar modal di Indonesia terhadap informasi non-ekonomi. Bagi investor, diharapkan mengamati kondisi perekonomian dan politik agar tidak mendapatkan return yang tidak diinginkan, karena kandungan informasi dari setiap peristiwa memiliki pengaruh yang berbeda. Emiten diharapkan memperhatikan informasi yang terkandung dalam peristiwa agar menjadi 
Maulana Faizal Hafidz \& Yuyun Isbanah. Analisis Komparatif Abnormal Return dan Trading Volume Activity berdasarkan Political Event (Event Study pada Pengesahan RUU KPK 2019)

pertimbangan strategi agar mendapatkan keuntungan dan loyalitas investor. Pemerintah juga diharapkan untuk pro-aktif dalam menyikapi informasi yang terkandung dalam peristiwa agar membuat kebijakan yang tepat dan membuat iklim ekonomi yang stabil dan terkendali.

Keterbatasan penelitian ini adalah event windows yang cukup singkat, yaitu 5 hari sebelum dan 5 hari sesudah Pengesahan Revisi Undang-Undang KPK sehingga pasar belum sepenuhnya dapat diartikan bereaksi terhadap informasi yang diterima investor. Penelitian ini hanya menggunakan pendekatan model market adjusted model. Penelitian selanjutnya diharapkan menambah durasi event date dan menambah model pendekatan mean adjusted model dan market model untuk menentukan expected return.

\section{DAFTAR PUSTAKA}

Adnan, A. T. M. (2019). Does Market React To Tax Reduction News? An Empirical Study On Corporate Tax Reduction Of Bangladesh In 2017-18. Journal of Business, Management, and Education. 17(2), 286-308.

Agatha, G., \& Suhadak. (2019). Uji Beda Abnormal Return, Trading Volume dan Market Capitalization Sebelum dan Sesudah Pengumuman Kebijakan Harga Jual DMO Batubara (Studi pada Perusahaan Subsektor Pertambangan Batubara yang Listing di BEI Tahun 2018). Jurnal Administrasi Bisnis (JAB)|Vol, 70(1), 45-52.

Ahmad, W., Khan, N., Usman, A., \& Ahmad, F. (2017). Stock Market Reaction to Political Event 'SitIn' ( Evidence from Pakistan ). Journal of Managerial Sciences, 11(1), 24-37.

Al farisi, G. salman, \& Nuzula, N. f. (2018). Analisis Perbedaan Reaksi Bursa Efek Indonesia Sebelum dan Sesudah Pengumuman Kebijakan Biodiesel 20 ( B20 ) ( Studi pada Perusahaan Kelapa Sawit Subsektor Perkebunan Tahun 2018 ). Jurnal Administrasi Bisnis (JAB), 72(1), 37-45.

Ariani, A., Topowijono, T., \& Sulasmiyati, S. (2016). Analisis Perbedaan Abnormal Return Dan Likuiditas Saham Sebelum Dan Sesudah Right Issue (Studi pada Perusahaan-Perusahaan yang Terdaftar di Bursa Efek Indonesia Tahun 2012-2015). Jurnal Administrasi Bisnis S1 Universitas Brawijaya, 33(2), 49-58.

BBC. (2019). Perppu KPK: Rancangan disiapkan untuk antisipasi keputusan Presiden Jokowi, langkah yang diragukan pengamat "dapat meredam aksi." Retrieved from https://www.bbc.com/indonesia/indonesia-49834678

Bimantara, R. A., Siswanto, E., \& Soesetio, Y. (2019). Pengumuman Perhitungan Baru Indeks LQ45 dan IDX30: Apakah Ada Reaksi pada Pasar Modal Indonesia? Jurnal Bisnis Dan Manajemen, $9(1), 27-40$.

Bouoiyour, J., \& Selmi, R. (2017). The Price of Political Uncertainty: Evidence from the 2016 U.S. Presidential Election and the U.S. Stock Markets. Journal of hyper articles on ligne, 33(0), 1-27.

Detik.com. (2019). UU KPK Direvisi, Ekonom : Rp 1,5 T keluar dari Pasar Modal. Retrieved from https://finance.detik.com/bursa-dan-valas/d-4709895/uu-kpk-direvisi-ekonom-rp-15-t-keluardari-pasar-modal

Dewi, N. P. A. S., Wahyuni, M. A., \& D, P. E. D. M. (2017). Pengaruh Pemilihan Gubernur DKI Tahun 2017 Terhadap Abnormal Return dan Volume Perdagangan Saham LQ45 di BEI. E-Journal S1 Ak Pendidikan Universitas Pendidikan Ganesha, 8(2).

Ghozali, I. (2016). Aplikasi Analisis Multivariete dengan IBM SPSS 23. Semarang. Badan Penerbit Universitas Diponegoro. 
Gratias, D., \& Mustanda, I. K. (2015). Pengaruh Peristiwa Kenaikan Harga BBM 18 November 2014 Pada Abnormal Return Saham dan Industri Transportasi Di BEI. Jurnal Manajemen, Strategi Bisnis Dan Kewirausahaan, 9(2), 166-176.

Hartono, J. (2017). Teori Portofolio dan Analisis Investasi. Yogyakarta. BPFE-Yogyakarta.

IDX. (2019). Laporan. Retrieved from https://www.idx.co.id/

Iyengar, M., Iyengar, N., \& Sampat, H. (2017). Impact of US election results on Indian stock market. International Jornal of Applied Research, 3(2), 9-13.

Kompas. (2019). Ekonom sebut Revisi UU KPK malah bikin investor kabur. Retrieved from https://money.kompas.com/read/2019/09/24/165236226/ekonom-sebut-revisi-uu-kpk-malahbikin-investor-kabur?page=all

Kompas. (2019). Presiden Jokowi tolak tuntutan untuk Cabut UU KPK. Retrieved from https://nasional.kompas.com/read/2019/09/23/18325521/presiden-jokowi-tolak-tuntutan-untukcabut-uu-kpk?page=all

Mahendra, I. K., \& Rasmini, N. K. (2019). Reaksi Pasar Terhadap Kenaikan Bank Indonesia 7-Day Reverse Repo Rate Tanggal 15 Agustus 2018. E-Jurnal Akuntansi, 27, 2066.

Mahmood, S., Irfan, M., \& Iqbal, S., Kamran, A. I. (2014). Impact of political events on stock market returns: empirical evidence from Pakistan. Journal of Asian Business Strategy, 30(1), 60-78.

Malhotra, N. K. (2009). Riset Pemasaran, Edisi keempat, Jilid 1. Jakarta: PT Indeks.

Masry, M. (2015). The Impact Of The Announcement Of Distribution Bonus Shares On Abnormal Returns And Trading Volume In The Egyptian Stock Market. The International Journal of Social Sciences and Humanities Invention, 2(12), 1717-1731.

Nestary A. N, Chandra, H. P. P. (2017). Analisis Pengaruh Pilkada Serentak Putaran I Dan II Tahun 2017 Terhadap Abnormal Return dan Volume Perdagangan Saham Pada LQ45 di Bursa Efek Indonesia. Jurnal Ilmu Komputer Dan Bisnis, 8(2), 2032-2049.

Ningsih, E., \& Cahyaningdyah, D. (2014). Reaksi Pasar Modal Indonesia Terhadap Pengumuman Kenaikan Harga BBM 22 Juni 2013. Management Analysis Journal, 1(3), 1-23.

Nisa, C., Astuti, M., \& Mariana, C. D. (2019). Dampak Merjer Dan Akuisisi Terhadap Abnormal Return Saham Perusahaan Di Indonesia Periode 2016-2018. Jurnal Riset Manajemen Sains Indonesia, 10(1), 44-70.

Oktaviani, R., Topowijono, T., \& Sulasmiyati, S. (2016). Analisis Perbedaan Trading Volume Activity Dan Abnormal Return Sebelum dan Sesudah Pengumuman Buy Back Saham (Studi pada Perusahaan yang Terdaftar di BEI yang Melakukan Buy Back Tahun 2012-2014). Jurnal Administrasi Bisnis S1 Universitas Brawijaya, 33(1), 120-126.

Pramana, A., \& Mawardi, W. (2012). Analisis Perbandingan Trading Volume Activity dan Abnormal Return Saham Sebelum dan Sesudah Pemecahan Saham. Diponegoro Journal Management, 1(1), $1-9$.

Pratama, I. G. B., Sinarwati, N. K., \& Dharmawan, N. A. S. (2015). Reaksi Pasar Modal Indonesia Terhadap Peristiwa Politik ( Event Study pada Peristiwa Pelantikan Joko Widodo Sebagai Presiden Republik Indonesia Ke-7 ). E-Journal S1 AK Universitas Pendidikan Ganesha. 3(1). 
Maulana Faizal Hafidz \& Yuyun Isbanah. Analisis Komparatif Abnormal Return dan Trading Volume Activity berdasarkan Political Event (Event Study pada Pengesahan RUU KPK 2019)

Purba, F., \& Handayani, S. R. (2017). Analisis Perbedaan Reaksi Pasar Modal Indonesia Sebelum Dan Sesudah Peristiwa Non Ekonomi (Studi pada Peristiwa Politik Pilkada DKI Jakarta 2017 Putaran Kedua). Jurnal Administrasi Bisnis (JAB), 51(1), 115-123.

Ramesh, S., \& Rajumesh, S. (2015). Stock Market Reaction to Political Events A Study of Listed Companies in Colombo Stock Exchange of Sri Lanka. Journal of Economics and Sustainable Development, 6(3), 131-139.

Ranco, G., Aleksovski, D., Caldarelli, G., Grčar, M., \& Mozetič, I. (2015). The effects of twitter sentiment on stock price returns. Journal of Plos One, 10(9), 1-21.

Rofiki, D., Topowijono, \& Nurlaily, F. (2018). Reaksi Pasar Modal Indonesia Akibat Peristiwa Pemilihan Gubernur DKI Jakarta Putaran II 2017 (Event Study Pada Saham Perusahaan Yang Terdaftar Di Indeks LQ45 Periode Februari-Juli 2017). Jurnal Administrasi Bisnis (JAB), 62(2), 185-193.

Rundengan, J. M., Mangantar, M., Maramis, J. B., \& Ratulangi, U. S. (2017). Reaksi Pasar Atas Pelantikan Sri Mulyani Sebagai Menteri Keuangan Pada 27 Juli 2016 (Studi Pada Saham LQ45). Jurnal EMBA: Jurnal Riset Ekonomi, Manajemen, Bisnis Dan Akuntansi, 5(3), 2731-2741.

Škrinjarić, T. (2019). Stock market reactions to brexit: Case of selected CEE and SEE stock markets. International Journal of Financial Studies, 7(7), 1-14.

Sugiyono. (2018). Metode Penelitian Kuantitatif, Kualitatif, dan R\&D. Bandung. Alfabeta.

Sukmaningrum, P. S., Madyan, M., \& Hendratami, A. (2019). Reaksi Pasar Saham Yang Terdaftar Dalam Jakarta Islamic Index ( JII ) Terhadap Pengumuman Penetapan Gubernur DKI Jakarta Tahun 2017. Jurnal Ekonomi Dan Bisnis Islam, 5(1), 1-14.

Tandelilin, E. (2010). Portofolio dan Investasi Teori dan Aplikasi. Yogyakarta. Kanisius.

Tempo. (2019). 5 Kampus yang menolak Revisi UU KPK. Retrieved from https://nasional.tempo.co/read/1245348/5-kampus-yang-menolak-revisi-uu-kpk/full\&view=ok

Wardhani, L. S. (2012). Reaksi Pasar Modal Indonesia Terhadap Peristiwa Pemilihan Gubernur DKI Jakarta Putaran II 2012. Jurnal Ilmiah Mahasiswa Fakultas Ekonomi Dan Bisnis Universitas Brawijaya, 1(1). 